\title{
Influence of pre-schooler and parent nutrition education on carotenoid levels of Mexican-heritage children
}

\author{
Marcel Horowitz ${ }^{1, *}$, Lucia L. Kaiser ${ }^{2}$, Rosa D Manzo ${ }^{3}$, Albert Aguilera ${ }^{4}$ (D), \\ L. Karina Diaz Rios ${ }^{5}$ and Karina Macias ${ }^{6}$ \\ 'University of California Cooperative Extension, Yolo County, Woodland, CA 95695, USA: ${ }^{2}$ Department of Nutrition, \\ University of California, Davis, CA, USA: ${ }^{3}$ Health Sciences Research Institute, University of California, Merced, CA, \\ USA: ${ }^{4}$ Department of Public Health, University of California, Merced, CA, USA: ${ }^{5}$ Division of Agriculture and Natural \\ Resources, University of California, Merced, CA, USA: 6 University of California Cooperative Extension, Fresno County, \\ CA, USA
}

Submitted 21 November 2018: Final revision received 23 September 2019: Accepted 28 October 2019: First published online 19 June 2020

\begin{abstract}
Objective: To determine the mediating effect of direct preschool and parent nutrition education on changes in skin carotenoids scores over 2 years in children of Mexican heritage.

Design: In a quasi-experimental, community-based study, two school districts were randomly assigned to either a comparison group (parent workshops unrelated to nutrition) or a childhood obesity prevention intervention group which included nutrition education at family nights for parents and at school for children. Changes in skin carotenoid intensity scores (diffCAROT, year 2015 minus 2013) were measured in children as a proxy for fruit and vegetable consumption using Resonance Raman Spectroscopy.

Setting: Two rural, low-income, school districts from a county in California's Central Valley.

Participants: 316 Mexican heritage families with children aged 3-8 years.

Results: Intervention group children improved over 2 years in skin carotenoid scores relative to comparison group children (diffCAROT mean +1419 (SD 9540) $v$. -3473 (SD 9272), $P=0.0001$ ). Parent attendance at nutrition education classes partially mediated the intervention effect on diffCAROT $(P=0.02)$. Controlling for child's age and other covariates, participation in preschool during the study had a significant positive effect on diffCAROT among intervention children compared with controls $(P<0.03)$, whereas no significant difference by group was observed among those not enrolled in preschool or already enrolled in elementary school.

Conclusions: Programmes that combine direct parent and preschool nutrition education may be effective in low-income Mexican heritage families to improve children's intake of fruit and vegetables.
\end{abstract}

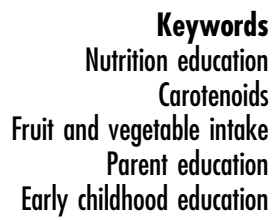

From lower academic performance to higher risk of chronic diseases in adulthood, the consequences of poor nutrition during childhood on physical and mental health are broad and well-documented ${ }^{(1-3)}$. Latino/Hispanic children, compared with non-Hispanic white children and youth, are disproportionately affected by diet-related health conditions, including obesity ( $25.8 v .14 \%)$ and type 2 diabetes ( 0.79 per 1000 v. $0 \cdot 17$ per 1000$)^{(4,5)}$. Latino households also report high rates of food insecurity $(18.5 \%)^{(6)}$, which negatively impact children's diet quality ${ }^{(7)}$.

Although Mexican-American children are more likely than non-Latino white and black children to meet the
Dietary Guidelines for Americans for fruit intake, vegetable intake is low among children of all race/ethnicities ${ }^{(8,9)}$. National trends also show a decrease in vegetable consumption from 2003 to 2010 among Mexican-American and non-Latino black children, compared with an increase among non-Latino white children ${ }^{(10)}$. Latino children from disadvantaged communities are more likely to consume less fruit, vegetables and whole grains, and more added sugars than recommended ${ }^{(11,12)}$.

To address health disparities, schools can be an important setting for improving dietary practices ${ }^{(13,14)}$. Although parent-related factors, such as parenting style and role 
modelling, have been consistently associated with children's diet quality ${ }^{(15-18)}$, school interventions that include a family engagement component are less common ${ }^{(13,19)}$.

The Niños Sanos, Familia Sana (NSFS) was a 3-year, childhood obesity prevention intervention using a community-based, participatory approach in a low-income, Mexican heritage population ${ }^{(20)}$. The intervention included nutrition education for parents at family nights and for children at school; a monthly voucher worth \$US25 to buy fruits and vegetables and an enhanced physical activity programme for children. Direct child nutrition education reached preschool and elementary school children.

Because early childhood is a critical age for developing lifelong eating patterns and self-regulation skills, we hypothesised that parent and child nutrition education, commencing at preschool age, would have the greatest impact on subsequent dietary changes in these children. Food preferences can shrink during preschool years and result in decreased diet variety in elementary school children $^{(21)}$. At the same time, young children begin to make individual food selections, thus representing a pivotal opportunity for intervening. Latino parents see themselves as a key influence on their child's diet, with school nutrition education as potentially having a positive effect ${ }^{(22)}$. However, some Latino immigrant parents perceive that negative dietary preferences coincide with their children's entry in the United States school system $^{(23)}$. They observe that their children begin to request westernised American foods, similar to the school foods they are served (such as pizza), and begin to reject traditional Mexican foods, such as stews and vegetable soups. Parents perceive this shift to be less healthy. Thus, culturally relevant interventions addressing child food preferences, parenting role modelling and the skills necessary to make healthy dietary choices may counter these changes in early childhood.

Therefore, a core objective of the NSFS direct education component was to provide young children with opportunities to explore healthy foods, with an emphasis on fruits and vegetables. The direct education component for parents sought to build positive parenting skills and reinforce school educational content at home to increase the likelihood of behaviour adoption and maintenance ${ }^{(23)}$.

Since preschool is the time of entry into school for many children, where they experience a food environment different than that at home, we expected preschool age to be the most promising time to develop healthy habits and to prevent declines in fruit and vegetable consumption. Thus, the purpose of the current study was to determine the mediating effect of direct pre-schooler and parent nutrition education delivered as part of a multi-level intervention, on changes over 2 years in skin carotenoids, a biomarker of fruit and vegetable intake, in children of Mexican heritage.

\section{Methods}

NSFS was a 3-year childhood obesity intervention that used a community-based, participatory research approach in a Mexican heritage audience ${ }^{(20)}$. The study targeted families with children aged 3-8 years from two rural school districts from the same county in California. Over $80 \%$ of the residents in these districts were of Mexican heritage. Located in California's Central Valley, both sites had an economic base that was primarily agricultural. The largest towns in both school districts were about $30-45 \mathrm{~min}$ from a city with a population of more than 500000 in 2010. Though the two districts were geographically and demographically similar, families in the comparison group lived in one of the four smaller communities all in the same school district, whereas intervention families were drawn from one larger community in the other school district. Criteria for selection of the sites included not having an active, comprehensive nutrition intervention at the time of selection (beyond routine or usual class activities) and agreement by local leaders and the school districts to work with researchers. At baseline in 2011, more than $90 \%$ of students were eligible for free or reduced-price lunches.

NSFS was a quasi-experimental study that randomly assigned the school districts by coin toss to either the intervention or comparison group. Eligibility requirements for families included: (1) having at least one child aged 3-8 years by 15 January 2012; (2) being of Mexican heritage (at least one parent) and (3) residing in one of the two selected school districts selected for the study. For households where two or more children were enrolled in the study, interviewers collected parent-reported dietary data for only one child who was 4-5 years old at baseline, or the youngest child if none were in that age range. This age range was selected to capture change as children transitioned from preschool to elementary school.

\section{Intervention components}

In the intervention community, children in preschool through third grade received evidence-based nutrition education curriculum developed by the University of California Cooperative Extension (UCCE) programme (https://uccal fresh.ucdavis.edu/curriculum/youth). Intervention curricula aligned with the California Department of Education state standards. Each lesson consisted of several activities, which could be done separately or all at once. UCCE nutrition educators provided training and technical assistance so that fidelity to lessons was maintained. These lessons were co-delivered by nutrition educators and classroom teachers.

Preschool and transitional kindergarten classes were provided with Happy, Healthy Me Nutrition Education lessons/kits during the course of the intervention (https:// ucanr.edu/sites/NSFSNutEduc/). Each lesson/kit included a central nutrition storybook that linked to several 
kindergarten readiness activities. All supplies necessary to carry out a multitude of hands-on, experiential learning opportunities to foster student interest and comprehension were provided. Teacher-facilitated group and individual self-direct and self-correcting activities allowed for a variety of instructional strategies throughout the week. Music, art, multiculturalism, science, food preparation, tasting, time outdoors, emotion regulation and social skills were integrated. Materials for both the teacher and student were available in English and Spanish. Kindergarten, first and second grade classes used the grade-appropriate Farm to Fork curriculum, which emphasises a connection between local food systems, garden-based learning and the establishment of healthy habits. These experiential lessons engage children in learning about healthy food and fitness choices. An emphasis is placed on eating a variety of nutritious foods, in alignment with MyPlate. The third grade classes received Reading Across My Pyramid curriculum. These literacy-based lessons taught general nutrition and food safety concepts.

Teachers recorded the number of lessons delivered and the total hours spent using the materials, including preparation and class time. NSFS research staff maintained Excel (version 14.07197.5000, Microsoft Corp., 2010) spreadsheets of participant assignments to each classroom for 3 years of the study. Prior to 2012, no nutrition education programmes had been provided by UCCE in the intervention school district. Starting in 2012, UCCE began phasing out nutrition education in the comparison district, most of which was provided to older, non-eligible children, until the end of the NSFS intervention.

A local Spanish-speaking nutrition educator, trained by a nutrition specialist, facilitated the family night parent education. Based on the Social Cognitive Theory, parent nutrition education was culturally adapted and focused on recommended key child obesity prevention messages ${ }^{(23)}$. Theoretical constructs were woven throughout the 3 years of sessions and included such things as monthly goal setting, positive reinforcement, building self-efficacy, skill building activities, environmental cue awareness and positive role modelling. Each session lasted about an hour and included food demonstrations and hands-on activities. Along with free nutrition education classes (family nights) for the parents, families in the intervention were provided with vouchers worth \$US25 a month to buy fresh produce at the local grocery store. The parents in the comparison community only received workshops unrelated to nutrition on topics of interest to the community, such as helping children succeed in school and managing stress.

Local Spanish-speaking promotoras (lay workers) helped with recruitment, community events, child care and data collection. Promotoras also phoned participants to schedule classes and kept a log of attendance on the day of class. Process evaluation data were collected for each session and entered into an Excel spreadsheet. To accommodate parents' needs, the promotoras provided child care and the educator led multiple sessions during the day and evening, covering the same topic each month. Twenty-two stand-alone classes were offered, including an orientation and a healthy food cook-off event.

\section{Outcome measure and other variables}

As a biomarker for fruit and vegetable consumption, skin carotenoid intensity scores (CAROT) were measured in the children using Resonance Raman Spectroscopy. This method exposes skin tissue at a single point to a beam of blue wavelength light $(\lambda=473-488 \mathrm{~nm})$ that is then bent to a green wavelength $(\lambda=510 \mathrm{~nm})$. Carotenoids are the only compounds known to bend a $473 \mathrm{~nm}$ light to $510 \mathrm{~nm}$ which enables the Resonance Raman Spectroscopy scanner to detect carotenoid levels in the skin. The resulting measurement is a score ranging from 0 to 70000 and above. Studies have demonstrated positive correlation between skin carotenoid levels and fruit and vegetable consumption in adults and children ${ }^{(24-26)}$. In Mexican-origin children, measurement of skin carotenoids is correlated with dietary intake of vegetables $(r=0.41, P=0.03, n 51)^{(25)}$. Also, changes in skin carotenoids closely follow plasma carotenoid changes, as shown in a controlled feeding trial providing a broad range of carotenoid intakes ${ }^{(26)}$. Duplicate measurements were recorded in the fall of 2013 (i.e. at the beginning of the second intervention year) and fall of 2015 (i.e. 2 months after the end of the intervention).

Starting in 2011, bilingual researchers, not involved in the delivery of the classes, collected baseline data on education, acculturation, marital status, employment, hours spent working outside the home and other socio-economic variables ${ }^{(20)}$. Interviews took place in homes, the field office or schools and in participants' preferred language (English or Spanish). Acculturation level was determined using the Brief Acculturation Rating Scale for Mexican Americans ${ }^{(27)}$, with a negative score indicating lower acculturation. To account for the dynamic nature of the acculturation process, country of birth and the percentage of life spent in the United States were also obtained.

\section{Data handling and analysis}

Data for this analysis were derived from the main NSFS database. Independent variables were created to define exposure of parents and children to nutrition education. To determine exposure level of parents, a continuous variable (attendance: range 0-22) was constructed, based on the parent class attendance logs. To determine the exposure level of children, the authors merged the number of hours of nutrition education provided by the teacher and UCCE staff records on the number of lessons delivered with NSFS class lists. Correlation between the number of lessons delivered and total teacher hours was very good $(r=0.71, P<0.0001)$. Since children aged $3-8$ years were eligible for the study, only some children were enrolled 
in preschool during the 3 years of the intervention. Thus, based on birth date of the child and class lists, it was possible to define school status as child was: $0=$ age eligible for preschool (3-5 years) but not enrolled; $1=$ age eligible for preschool and enrolled during either year 1 or 2 of the NSFS study; or 2 = too old for preschool, already in kindergarten or elementary school. By year 3 of the study, all NSFS children were old enough to be in kindergarten or elementary school. The outcome (i.e. dependent variable) was changed in children's skin carotenoid intensity scores (diffCAROT), based on the difference between measurements (fall 2015 minus fall 2013 average skin carotenoid scores). Thus, a positive sign on the change variable indicated improvement in this biomarker for fruit and vegetable intake.

SAS for Windows (version 9.3, 2010) was used in the analysis. Descriptive statistics were used to present means (or medians for non-normally distributed variables) and frequencies. For bivariate analyses, $\chi^{2}$ or Fisher's exact test was used for categorical variables and Student's $t$ test (normal distribution) or Wilcoxon tests (non-normal distribution), for continuous variables. The dependent variable (diffCAROT) was normally distributed, as determined by the Shapiro-Wilk's test.

ANOVA was used to examine the effects of group, parents' nutrition exposure and children's nutrition exposure on diffCAROT. Child's age was included as a covariate, along with skin carotenoid level in 2013, mother's birthplace (US or Mexico), mother's age and household participation in the Supplemental Nutrition Assistance Program (SNAP). For children, the analytical approach first determined whether an interaction between group and school status existed because of the possibility that comparison children might have received some routine classroom nutrition education through community programmes not accounted for by the research team.
Though no nutrition education classes for parents were offered in the comparison community, some mothers in the intervention community attended no (or very few) classes. Thus, the analytical approach sought to determine how much of the intervention group effect on children's diffCAROT scores was mediated by the parents' level of participation in adult nutrition classes. Mediation analysis has been used by researchers to identify and refine critical components of multi-level interventions ${ }^{(28)}$. While mediators often include child-, family-, school- or peer-level determinants of behavioural outcomes ${ }^{(29)}$, process indicators may be used. Significance level was $P<0.05$.

\section{Results}

The NSFS database contained 392 children with diffCAROT values, measured from 2013 to 2015. Complete data for the subsample analyses, including only one child per household, were available for 212 children in the intervention group and 104 in the comparison group ( $n$ 316). As shown in Table 1, these groups did not differ significantly at baseline in child's gender or BMI at baseline; mother's education; household income (total monthly or as a proportion of the federal poverty line) or participation in WIC. However, intervention children and parents were significantly older compared with controls $(P=0.02, \quad P=0.03$, respectively). There was a tendency for more of the comparison mothers to have a Mexican birthplace, compared with intervention mothers $(P=0.07)$. More comparison than intervention households were currently participating in SNAP $(P=0 \cdot 01)$.

As shown in Table 2, significant differences in school status during the study were evident among the groups $(P=0.0001)$. Among children in the intervention group, $27 \%$ ( $n$ 58) were exposed to the UCCE preschool nutrition education programme, compared with $14 \%\left(\begin{array}{ll}n & 15\end{array}\right)$

Table 1 Characteristics of Mexican-heritage children and their families by study group $(n 316)$

\begin{tabular}{|c|c|c|c|c|c|}
\hline \multirow[b]{2}{*}{ Variable } & \multicolumn{2}{|c|}{ Intervention ( $n$ 212) } & \multicolumn{2}{|c|}{ Comparison (n 104) } & \multirow[b]{2}{*}{$P$} \\
\hline & Median & IQR & Median & IQR & \\
\hline Child's age (years), 2012 & $6 \cdot 1$ & $1 \cdot 8$ & $5 \cdot 6$ & 1.9 & $0.02^{*}$ \\
\hline Mother's age (years), 2012 & $34 \cdot 0$ & $10 \cdot 2$ & $31 \cdot 1$ & $9 \cdot 7$ & $0.03^{*}$ \\
\hline Mother's education (years) & $9 \cdot 0$ & 6 & $9 \cdot 0$ & 6 & $0 \cdot 28^{*}$ \\
\hline Income (proportion of Federal Poverty Level), 2012 & 0.79 & 0.50 & 0.77 & 0.52 & $0.42^{*}$ \\
\hline Child's BMI z-score, 2012 & 0.96 & 1.00 & 0.96 & $1 \cdot 10$ & $0.98 \dagger$ \\
\hline Skin carotenoid intensity score, 2013 & 26972 & 9350 & 28161 & 8645 & $0.27 \dagger$ \\
\hline Skin carotenoid intensity score, 2015 & 28390 & 8582 & 24687 & 8465 & $0.0003 \dagger$ \\
\hline \multirow[t]{2}{*}{ Skin carotenoid intensity score, difference (year 2015-2013) } & +1419 & 9540 & -3473 & 9272 & $0.0001 \dagger$ \\
\hline & $n$ & $\%$ & $n$ & $\%$ & \\
\hline Child's gender (male) & 108 & $50 \cdot 9$ & 44 & $42 \cdot 3$ & $0.15 \ddagger$ \\
\hline Mother's birthplace (Mexico) & 164 & $77 \cdot 3$ & 90 & 86.5 & $0.07 \ddagger$ \\
\hline Enrolled in SNAP (yes), 2015 & 92 & 43.5 & 61 & $58 \cdot 7$ & $0.01 \ddagger$ \\
\hline Enrolled in WIC (yes), 2015 & 73 & $36 \cdot 8$ & 48 & $46 \cdot 2$ & $0.11 \neq$ \\
\hline
\end{tabular}

IQR, interquartile range; SNAP, Supplemental Nutrition Assistance Program; WIC, Special Supplemental Nutrition Program for Women, Infants, and Children.

*Analysed by Wilcoxon test.

†Analysed by $t$ test.

$\ddagger$ Analysed by Fisher’s Exact test. 
Table 2 Exposure to preschool nutrition education among Mexican-heritage children and parents, 2012-2015

\begin{tabular}{|c|c|c|c|c|c|c|c|c|c|c|c|}
\hline \multirow[b]{2}{*}{ Variable } & \multicolumn{5}{|c|}{ Intervention } & \multicolumn{5}{|c|}{ Comparison } & \multirow[b]{2}{*}{$P^{*}$} \\
\hline & $n$ & Mean & SD & Median & IQR & $n$ & Mean & SD & Median & IQR & \\
\hline \multicolumn{12}{|c|}{ Number of nutrition lessons delivered to children at school } \\
\hline Year 1 & 212 & $3 \cdot 8$ & $2 \cdot 7$ & $4 \cdot 0$ & $3 \cdot 0$ & 96 & $2 \cdot 3$ & $3 \cdot 0$ & 0.0 & $4 \cdot 0$ & \multirow[t]{4}{*}{0.004} \\
\hline Year 2 & 212 & 4.9 & $2 \cdot 3$ & $5 \cdot 0$ & $3 \cdot 0$ & 104 & 1.5 & $2 \cdot 5$ & 0.0 & $2 \cdot 0$ & \\
\hline Year 3 & 130 & $5 \cdot 0$ & 0.2 & $5 \cdot 0$ & 0.0 & 104 & 0.0 & 0.0 & 0.0 & 0.0 & \\
\hline All years & 130 & $14 \cdot 0$ & 4.4 & $13 \cdot 0$ & $5 \cdot 0$ & 96 & $3 \cdot 8$ & $4 \cdot 1$ & $3 \cdot 0$ & $7 \cdot 0$ & \\
\hline \multicolumn{12}{|c|}{ Number of teacher hours spent in school-based nutrition education } \\
\hline Year 1 & 188 & $26 \cdot 0$ & 25.7 & 18.5 & $20 \cdot 0$ & 96 & 21.7 & $30 \cdot 6$ & 0.0 & 34 & \multirow[t]{4}{*}{0.0001} \\
\hline Year 2 & 212 & $23 \cdot 6$ & $23 \cdot 1$ & 17.5 & 17.5 & 104 & $6 \cdot 3$ & $10 \cdot 1$ & 0.0 & 13.5 & \\
\hline Year 3 & 130 & $15 \cdot 9$ & $11 \cdot 3$ & $12 \cdot 0$ & $19 \cdot 0$ & 104 & 0.0 & 0.0 & 0.0 & 0.0 & \\
\hline All years & 110 & 74.9 & 43.6 & $59 \cdot 8$ & 61.5 & 96 & 27.9 & $33 \cdot 8$ & $21 \cdot 3$ & 37 & \\
\hline \multicolumn{12}{|c|}{ Number of nutrition classes that parents attended (range: 0-22) } \\
\hline All years & 212 & $9 \cdot 7$ & $6 \cdot 9$ & $10 \cdot 0$ & $13 \cdot 0$ & 104 & 0.0 & 0.0 & 0.0 & 0.0 & 0.0001 \\
\hline Variable & \multicolumn{3}{|c|}{$n$} & \multicolumn{2}{|l|}{$\%$} & \multicolumn{2}{|c|}{$n$} & \multicolumn{2}{|r|}{$\%$} & \multicolumn{2}{|c|}{$P^{*}$} \\
\hline \multicolumn{12}{|l|}{ School status (2012-2015) } \\
\hline Not enrolled in preschool, age-eligible & & 14 & & $6 \cdot 6$ & & & 41 & & 39.4 & \multirow{3}{*}{\multicolumn{2}{|c|}{0.0002}} \\
\hline Enrolled in preschool, age- eligible & & 58 & & $27 \cdot 4$ & & & 15 & & 14.4 & & \\
\hline $\begin{array}{l}\text { No preschool, not age-eligible, already } \\
\text { in elementary school }\end{array}$ & & 40 & & 66.0 & & & 48 & & $46 \cdot 2$ & & \\
\hline
\end{tabular}

IQR, interquartile range; SD, standard deviation.

${ }^{\star}$ Analysed by Wilcoxon two-sample test.

Table 3 Pearson correlation coefficients of nutrition education and other variables with change in Mexican-heritage children's Skin Carotenoid Intensity Scores (diffCAROT) (n 316)

\begin{tabular}{lccl}
\hline Variable & $n$ & $r$ & \multicolumn{1}{c}{$P^{*}$} \\
\hline \multicolumn{4}{l}{ Children's exposure to nutrition education: } \\
Number of lessons, all years & 226 & +0.22 & 0.0008 \\
Number of teacher hours, all years & 282 & +0.15 & 0.01 \\
Mother's exposure to nutrition education & (number of classes) \\
Intervention group only & 212 & +0.22 & 0.001 \\
Both groups & 316 & +0.29 & 0.0001 \\
Child's age at baseline (years) & & -0.18 & 0.001 \\
Mother's education (years) & & -0.03 & 0.65 \\
Mother's age (years) & & -0.04 & 0.43 \\
Incomet & & -0.16 & 0.008 \\
\hline
\end{tabular}

*Analysed by Pearson correlation coefficient.

†As a proportion of the federal poverty level.

exposed to routine preschool programmes in the comparison community. No significant difference was observed in enrolling or not an age-eligible child (3-4 years old) in preschool among mothers who finished their schooling in Mexico $(18 \%, n 35)$ or the US $(16 \%, n 20)(P=0.36)$. Similarly, mother's birthplace was unrelated to child's exposure to preschool (data not shown). Children's overall exposure to nutrition education, as reflected in both number of lessons and total teacher time spent in delivery, was significantly higher in the intervention than comparison group. In the intervention group, the median number of classes parents attended was 10 (of twenty-two sessions offered), with $25 \%$ attending three or fewer; no classes were offered in the comparison community.

The unadjusted correlation coefficients are shown in Table 3. Attendance at parent nutrition classes was positively correlated with increase in skin carotenoids (diffCAROT) over time. Number of lessons and teacher hours spent in delivery were also positively correlated with diffCAROT.

Since parent attendance at nutrition education classes was significantly related to both the group (Table 2 ) and the outcome variables (Table 3), Table 4 presents the role of this component in mediating the overall effect of the multifaceted intervention on diffCAROT scores (2015-2013 measurements). Model 1 in Table 4 shows the magnitude of the full intervention on the outcome, controlling for potential confounders $(+5016$ units, $P<0 \cdot 0001)$. Model 2 in Table 4, which did not include the group variable, shows much smaller effect on the outcome of parent attendance only ( +337 units per class, $P<0.0001)$. In model 3 in Table 4, a partial mediation effect of parent attendance on the relationship between group and outcome was observed $(+2970$ units, $P<0.02)$.

Figure 1 shows that the effect of child nutrition education on diffCAROT depends on whether or not the child was exposed to preschool from 2012 to 2014 (all children were in kindergarten or higher in 2014-15). The interaction between child's preschool status and group was $P=0.06$. Controlling for child's age, CAROT in 2013, mother's age, mother's birthplace and SNAP, participation in preschool during the study had a significant positive effect on the diffCAROT outcome among intervention children compared with controls $(P<0.03)$. No significant difference by group was observed among those not enrolled in preschool or already enrolled in elementary school.

\section{Discussion}

Mexican heritage families participating in a multifaceted, community-based intervention that included direct 
Table 4 Regression analysisł of mediation due to parent nutrition education on change (2015-2013) in Mexican-heritage children’s Skin Carotenoid Intensity Scores (diffCAROT) $(n$ 316)

\begin{tabular}{|c|c|c|c|c|c|c|}
\hline \multirow[b]{2}{*}{ Variables } & \multicolumn{2}{|c|}{ Model 1} & \multicolumn{2}{|c|}{ Model 2} & \multicolumn{2}{|c|}{ Model 3} \\
\hline & Estimate & SE & Estimate & SE & Estimate & SE \\
\hline Intercept & +36038 & 3444 & +27348 & 3077 & +32415 & 3698 \\
\hline Group ( $0=$ comparison; $1=$ treatment) & $+5016 \S$ & 930 & $\mathrm{~N} / \mathrm{A}$ & & $+2970^{*}$ & 1222 \\
\hline $\begin{array}{l}\text { Parent attendance (No. of classes, 0-22) } \\
F \text {-value }\end{array}$ & $\begin{array}{c}\mathrm{N} / \mathrm{A} \\
38.18\end{array}$ & & $+337 \S$ & 62 & $+207 \dagger$ & 81 \\
\hline$R^{2}$ & 0.43 & & 0.43 & & 0.44 & \\
\hline
\end{tabular}

¥All models are adjusted for initial CAROT scores in 2013, mother's birthplace (US or Mexico), mother's age and household participation in the Supplemental Nutrition Assistance Program (SNAP) in 2015.

+ Indicates increase in children's skin carotenoid scores from 2013 to 2015.

${ }^{*} P<0.05 ; \dagger P<0.01 ; \S P<0.0001$

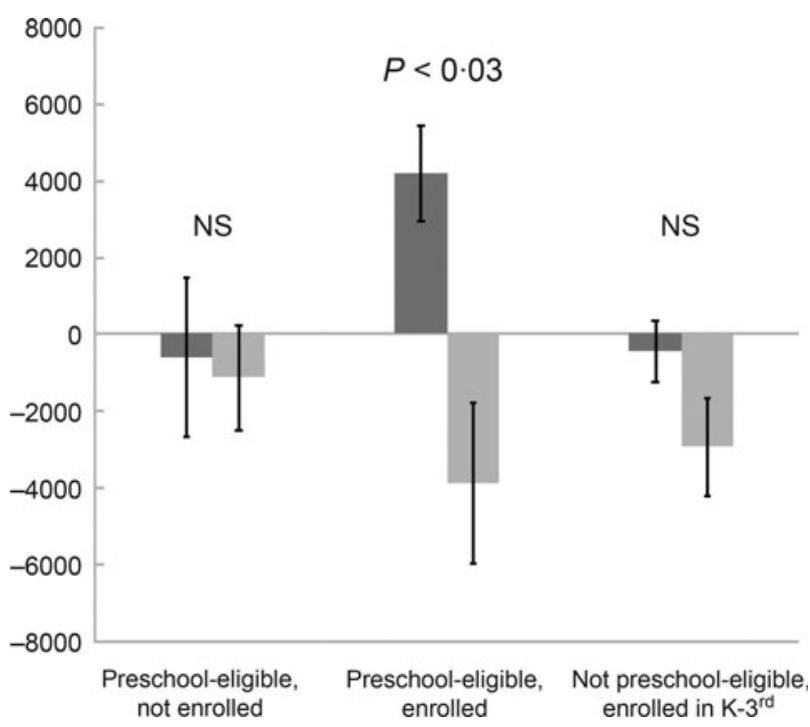

Fig. 1 Change from 2013 to 2015 in Skin Carotenoid Intensity Score (diffCAROT) in response to child exposure to preschool nutrition education from 2012 to 2014. Controlling for child's age and other covariates. Bars represent standard errors. Participation in preschool during the study had a significant positive effect on CAROT $(P<0.03)$. $匚$, Intervention; $\square$, comparison

nutrition education to children and parents showed overall greater improvement over 2 years in children's skin carotenoid intensity scores than families from a comparison community. Along with direct nutrition education, the full NSFS intervention also promoted physical activity at school and provided participating families with a monthly voucher to purchase produce. This analysis showed that parent nutrition education partially mediated the NSFS intervention effect. Although diffCAROT level was positively correlated with children's exposure to nutrition education (no. of teacher hours and no. of lessons), in the multivariate analyses, significant improvement in skin carotenoid scores was only observed among intervention children enrolled in preschool. In other words, an interactive effect was observed between group and school status during the study period. This suggests exposure to preschool in the intervention group contributed to improving fruit and vegetable intake.

Researchers have reported the short-term benefits of early childhood education, including higher later academic achievement, school attendance, better social interactions, more appropriate class behaviour and higher emotional maturity ${ }^{(30)}$. The nutrient adequacy achieved by participating in school meal programmes plausibly contributes to the cognitive benefits seen in children attending preschool $^{(1,31)}$. In a mediation analysis, a multilevel intervention that targeted kindergarten children in Europe (the Toy-Box study) improved some child- and family-level mediators but did not significantly change child snacking behaviours, as reported by parents ${ }^{(29)}$. Only a few studies have examined the benefits of direct early nutrition education interventions targeting pre-schoolers ${ }^{(32-34)}$. A US study reported increased vegetable intake, but not fruit intake, among low-income preschool children in child care centres receiving direct parent and child education over a 6-10 week period ${ }^{(32)}$. A study conducted in Ecuador over a 7-month period found greater improvement in parentreported child snacking behaviours in pre-schoolers receiving direct child care and home intervention components, compared with those only reached in the child care setting ${ }^{(34)}$. Other studies have reported mixed or no effects of direct pre-schooler nutrition education on food choices, with interventions providing opportunities for skill-building 
and exposure to fruits and vegetables showing the most promising results $32,33,35,36)$

Previous studies have relied on parent-reported measures of their children's dietary behaviours, using measures that are subject to bias. Also, the follow-up periods were short-term ( $<1$ year). Our study adds to the literature by measuring changes in a biomarker of fruit and vegetable intake over a 2-year period, in preschool and elementary school-aged children. In another school-based intervention, skin carotenoid measures were correlated with student-reported carotenoid intakes from FFQ, but both measures declined in fourth grade children during the 1-year follow-up ${ }^{(37)}$. No controls were included in the analysis, and children were older compared with the age range in the NSFS study. However, our study found no differences in diffCAROT between groups in children who were in kindergarten to third grade at baseline.

There are several reasons why attendance at preschool might increase fruit and vegetable consumption, regardless of formalised nutrition education programming. The first is that often these schools provide snacks and meals to the children. If they are government sponsored schools, or if the meals are partially reimbursed, then a minimum of fruits and vegetables must be included ${ }^{(38)}$. Most of the children in the NSFS intervention and comparison communities were eligible for free or reduced-price school meals. This means children from both arms of the study were likely exposed to a variety of nutritious options, including fruits and vegetables, leading to greater consumption. However, improvements in skin carotenoid scores were only seen among children in the intervention group, which indicates availability at school is not enough. In preschool settings, children usually eat in a family-style manner, which leads to increased social pressure to eat what others are eating. This positive peer pressure can result in children being more willing to eat fruits and vegetables ${ }^{(35)}$, if they are available and intentionally featured. Teachers may also eat the same meal, adding a positive model for the students ${ }^{(39)}$. Finally, it is also worth noting that aspects thought to support a child's healthy diet and growth (such as structured nap times, food-related books, pretend kitchens, structured physical activity areas and outdoor gardens) are commonly integrated into most preschools.

Preschool participation in both study communities was low compared with national estimates for Hispanic children $^{(40,41)}$; yet, enrolment of age-eligible children was even lower in the comparison community. Parent characteristics, such as age, income, education and place of birth, have been associated with preschool participation ${ }^{(40,42)}$. While mothers in the intervention group were older than controls, they had similar education attainment. No effect of mother's birthplace on preschool participation was observed. Thus, preschool participation might be better explained by structural and contextual factors - rather than cultural factors - that perniciously affect the ability of low-income Latino families to successfully navigate the education environment ${ }^{(41,43)}$. The extent to which structural and contextual factors differentially played in the study communities was beyond the scope of this study but warrant further investigation. One explanation is that the nature of the intervention may have attracted families with higher levels of motivation to be involved in their children's education. This also potentially implies a certain degree of selection bias occurred despite the cluster randomisation of the communities.

Parent involvement has been identified as a key component of interventions to improve child's nutritional status ${ }^{(39,40)}$. Interventions with a parent component have been found to be more effective when the content closely aligns with the information covered in the child component and are simple and actionable, framed in behaviour change theory and culturally relevant ${ }^{(39,40)}$. The NSFS parent nutrition education was designed to balance cultural relevance at home with positive nutrition behaviour changes promoted at school. It also aimed to address parents' concerns about changing child preferences through exposure to non-traditional food at school ${ }^{(23)}$. In addition, parent sessions were delivered in Spanish (audience's preferred language) by culturally competent educators assisted by promotoras, who had similar background and live in the same community as participating parents. By reinforcing nutrition messages received at school, these focused efforts to the parents likely contributed not only to the significant increase in skin carotenoid scores among intervention children enrolled in preschool but also to the mitigated decrease trend in this biomarker among older intervention children, compared with the control groups.

There are several limitations to acknowledge. Measurement of skin carotenoid scores commenced in fall after the first year of the study; in other words, a true baseline was not measured. However, there were no significant differences between the intervention and comparison groups at the first measurement. The study design randomised communities (not individuals) into the two groups, raising the possibility that unmeasured community or family characteristics may have influenced the results. To measure children's exposure, teacher-reported hours spent in nutrition education and number of lessons delivered were used in the analysis but there were no data to confirm that individual children were attentive or even present on all days that nutrition education was offered in that classroom. Another potential limitation is that during the first 2 years, older non-eligible siblings of control children may have received some nutrition education that influenced their younger siblings. We are unable to quantify if such contamination occurred. However, NSFS nutrition education did not commence in the intervention community before 2012, so such an effect would have presented a bias against the intervention which was significant at $P<0.0001$ (model 1, Table 4). 
However, strength of the current study was utilising skin carotenoid measurement as biomarker of fruit and vegetable intake in this underserved population. Moreover, the study was able to monitor changes in this outcome over a 2 -year period, rather than only rely on a short-term follow-up.

Our findings have implications for public health professionals who must allocate scarce resources to programmes that have the greatest impact. Parent and direct preschool nutrition education may be especially effective to improve children's intake of fruit and vegetables, especially when targeting low-income families and are culturally relevant in the context of both school and home. Economists estimate that for every dollar invested in early childhood education, society benefits fourfold to tenfold ${ }^{(44)}$. Our current research adds to the list of possible positive outcomes for early childhood education. An improvement in skin carotenoid levels indicates increased patterns of fruit and vegetable consumption. Increases in fruit and vegetable consumption in early childhood are likely to track throughout life, improving long-term health ${ }^{(45,46)}$. Government programmes that aim to improve dietary practices should consider investing in early childhood nutrition education, especially in disadvantaged communities.

\section{Acknowledgements}

Acknowledgements: The authors would like to acknowledge the support received towards the completion of this research project. The authors are grateful for the help from the UCCE Fresno County office, the UC CalFresh program, the California Expanded Food and Nutrition Education Program, the entire NSFS team, Judith Silva for delivering parent education classes, and the intervention and comparison communities for their participation. Financial support: This material is based upon work that is supported by the National Institute of Food and Agriculture, U.S. Department of Agriculture, under award number 201168001-30167 and by CA-D-NTR-2117-H; partially supported by Peter J. Shields and Henry A. Jastro Research Award; and Pharmanex for graciously loaning the BioPhotonic Scanner. These funders had no role in the design, analysis or writing of this article. Conflict of interest: All authors declare no conflicts of interest derived from this research. Authorship: M.H. contributed to the development of the research questions, the study design, development of intervention materials used in the study and writing the article. L.L.K. contributed to development of research questions, study design; data analysis and interpretation of findings; trained local educator for parent classes; developed curriculum used for parent education. R.D.M. contributed to the development of the research questions, the study design, interpretation of findings, development of intervention and writing the article. A.A. contributed to the development of research questions, the study design, interpretation of findings, developed curriculum used for parent education. L.K.D.R. contributed to write the introduction and discussion; reviewed and provided critical input on the manuscript. K.M. contributed to the database and preparation of the manuscript. Ethics of human subject participation: This study was conducted according to the guidelines laid down in the Declaration of Helsinki and all procedures involving human participants were approved by the University of California, Davis Institutional Review Board. Written informed consent was obtained from all participants.

\section{References}

1. Burrows T, Goldman S, Pursey K et al. (2017) Is there an association between dietary intake and academic achievement: a systematic review. J Hum Nutr Diet 30, $117-140$.

2. Cook LT, O'Reilly GA, Goran MI et al. (2014) Vegetable consumption is linked to decreased visceral and liver fat and improved insulin resistance in overweight Latino youth. J Acad Nutr Diet 114, 1776-1783.

3. Sahoo K, Sahoo B, Choudhury AK et al. (2015) Childhood obesity: causes and consequences. I Family Med Prim Care 4, 187-192.

4. Hales CM, Carroll MD, Fryar CD et al. (2017) Prevalence of obesity among adults and youth: United States, 2015-2016. US Dept of HHS, CDC and Prev, NCHS Data Brief. No. 288. https://www.cdc.gov/nchs/products/databriefs/db288. html (accessed October 2018).

5. Dabelea D, Mayer-Davis EJ, Saydah S et al. (2014) Prevalence of type 1 and type 2 diabetes among children and adolescents from 2001 to 2009. JAMA 311, $1778-1786$.

6. Coleman-Jensen A, Rabbitt MP, Gregory CA et al. (2017) Household Food Security in the United States in 2016. Report no. ERR-237. Washington, DC: U.S. Department of Agriculture, Economic Research Service. 44 p. https:// www.ers.usda.gov/publications/pub-details/?pubid $=84972$ (accessed March 2018).

7. Holben DH \& Marshall MB (2017) Position of the Academy of Nutrition and Dietetics: food insecurity in the United States. J Acad Nutr Diet 117, 1991-2002.

8. Di Noia J \& Byrd-Bredbenner C (2014) Determinants of fruit and vegetable intake in low-income children and adolescents. Nutr Rev 72, 575-90.

9. Hiza HA, Casavale KO, Guenther PM et al. (2013) Diet quality of Americans differs by age, sex, race/ethnicity, income, and education level. J Acad Nutr Diet 113, 297-306.

10. Kim SA, Moore LV, Galuska D et al. (2014) Vital signs: fruit and vegetable intake among children-United States, 2003-2010. MMWR Morb Mortal Wkly Rep 63, 671-676.

11. Quandt SA, Trejo G, Suerken CK et al. (2016) Diet quality among preschool-age children of Latino migrant and seasonal farmworkers in the United States. J Immigr Minor Health 18, 505-512.

12. Wilson TA, Adolph AL \& Butte NF (2009) Nutrient adequacy and diet quality in non-overweight and overweight Hispanic children of low socioeconomic status: the Viva la Familia Study. J Am Diet Assoc 109, 1012-1021. 
13. Branscum P \& Sharma MW (2011) A systematic analysis of childhood obesity prevention interventions targeting Hispanic children: lessons learned from the previous decade. Obes Rev 12, e151-e158.

14. Waters E, de Silva-Sanigorski A, Burford BJ et al. (2011) Interventions for preventing obesity in children. Cochrane Database Syst Rev issue 12, CD001871.

15. Birch LL \& Doub AE (2014) Learning to eat: birth to age $2 \mathrm{y}$. Am J Clin Nutr 99, 723S-728S

16. Futrell Dunaway L, Carton T, Ma P et al. (2017) Beyond food access: the impact of parent-, home-, and neighborhoodlevel factors on Children's diets. Int J Environ Res Public Health 14, 662-672.

17. Penilla C, Tschann JM, Deardorff J et al. (2017) Fathers' feeding practices and children's weight status in Mexican American families. Appetite 117, 109-116.

18. Shloim N, Edelson LR, Martin N et al. (2015) Parenting styles, feeding styles, feeding practices, and weight status in 4-12 year-old children: a systematic review of the literature. Front Psychol 6, 1849.

19. Wang Y, Cai L, Wu Y et al. (2015) What childhood obesity prevention programmes work? A systematic review and meta-analysis. Obes Rev 16, 547-565.

20. de la Torre A, Sadeghi B, Green RD et al. (2013) Niños Sanos, Familia Sana: Mexican immigrant study protocol for a multifaceted CBPR intervention to combat childhood obesity in two rural California towns. BMC Public Health 13, 1033. doi: 10.1186/1471-2458-13-1033.

21. Lafraire J, Rioux C, Giboreau A et al. (2016) Food rejections in children: cognitive and social/environmental factors involved in food neophobia and picky/fussy eating behavior. Appetite 96, 347-357.

22. Flores G, Maldonado J \& Durán P (2012) Making tortillas without lard: Latino parents' perspectives on healthy eating, physical activity, and weight-management strategies for overweight Latino children. J Acad Nutr Diet 112, 81-89.

23. Kaiser L, Martinez J, Horowitz M et al. (2015) Adaptation of a culturally relevant nutrition and physical activity program for low-income, Mexican-origin parents with young children. Prev Chronic Dis 12, E72.

24. Aguilar SS, Wengreen HJ \& Dew J (2015) Skin carotenoid response to a high-carotenoid juice in children: a randomized clinical trial. J Acad Nutr Diet 115, 1771-1778.

25. Aguilera AL, Stewart CP, de la Torre A et al. (2018) Feasibility of skin carotenoids as a biomarker of vegetable intake among Mexican-Origin children in a community setting: a crosssectional pilot study. J Epidem Res 4, 1-7.

26. Jahns L, Johnson LK, Mayne ST et al. (2014) Skin and plasma carotenoid response to a provided intervention diet high in vegetables and fruit: uptake and depletion kinetics. $A m$ J Clin Nutr 100, 930-937.

27. Cuellar I, Arnold B \& Maldonado R (1995) Acculturation rating scale for Mexican Americans-II: a revision of the original ARSMA scale. Hisp J Behav Sci 17, 275-304.

28. Lockwood CM, DeFrancesco CA, Elliot DL et al. (2010) Mediation analyses: applications in nutrition research and reading the literature. J Am Diet Assoc 110, 753-762.

29. Lambrinou CP, van Stralen MM, Androutsos O et al. (2019) Mediators of the effectiveness of a kindergarten-based, family-involved intervention on pre-schoolers' snacking behaviour: the ToyBox-study. Public Health Nutr 22, 157-163.

30. Bakken L, Brown N \& Downing B (2017) Early childhood education: the long-term benefits. J Res Child Educ 31, 255-269.

31. John CC, Black MM \& Nelson CA (2017) Neurodevelopment: the impact of nutrition and inflammation during early to middle childhood in low-resource settings. Pediatrics 139, Suppl. 1, S59-S71.

32. Williams PA, Cates SC, Blitstein JL et al. (2014) Nutritioneducation program improves preschoolers' at-home diet: a group randomized trial. J Acad Nutr Diet 114, 1001-1008.

33. Joseph LS, Gorin AA, Mobley SL et al. (2015) Impact of a short-term nutrition education child care pilot intervention on preschool children's intention to choose healthy snacks and actual snack choices. Child Obes 11, 513-520.

34. Romo ML \& Abril-Ulloa V (2018) Improving nutrition habits and reducing sedentary time among preschool-aged children in Cuenca, Ecuador: a trial of a school-based intervention. Prev Chronic Dis 15, E96.

35. DeCosta P, Møller P, Frøst MB et al. (2017) Changing children's eating behavior: a review of experimental research. Appetite 113, 327-57.

36. Nekitsing C, Hetherington MM \& Blundell-Birtill P (2018) Developing healthy food preferences in preschool children through taste exposure, sensory learning, and nutrition education. Curr Obes Rep 7, 60-67.

37. Beccarelli LM, Scherr RE, Dharmar M et al. (2017) Using skin carotenoids to assess dietary changes in students after 1 academic year of participating in the Shaping Healthy Choices program. J Nutr Educ Behav 49, 73-78.

38. Food and Nutrition Services (2018) Nutrition standards for school meals. Washington, DC: USDA. https://www.fns. usda.gov/school-meals/nutrition-standards-school-meals (accessed October 2018).

39. Black AP, D'Onise K, McDermott R et al. (2017) How effective are family-based and institutional nutrition interventions in improving children's diet and health? A systematic review. BMC Public Health 17, 818.

40. Ling J, Robbins LB, Wen F et al. (2017) Lifestyle interventions in preschool children: a meta-analysis of effectiveness. Am J Prev Med 53, 102-112.

41. National Center for Education Statistics. Preschool and kindergarten enrollment. United States: Institute of Education Sciences. https://nces.ed.gov/programs/coe/indicator_cfa. asp\#info (accessed October 2018).

42. Ansari A (2017) The selection of preschool for immigrant and native-born Latino families in the United States. Early Child $\operatorname{Res} Q \mathbf{4 1}, 149-160$.

43. Crosnoe R, Purtell KM, Davis-Kean P et al. (2016) The selection of children from low-income families into preschool. Dev Psychol 52, 599-612.

44. Reynolds AJ \& Temple JA (2008) Cost-effective early childhood development programs from preschool to third grade. Annu Rev Clin Psychol 4, 109-139.

45. Grimm KA, Kim SA, Yaroch AL et al. (2014) Fruit and vegetable intake during infancy and early childhood. Pediatrics 134, Suppl. 1, S63-S69.

46. Mennella JA (2014) Ontogeny of taste preferences: basic biology and implications for health. Am J Clin Nutr 99, 704S-711S. 